\title{
Multi Terrain Surveillance Drone
}

\author{
Rohit N Nair, Prasanth P Menon, Roy Baiju, Sreelakshmi L S, V Kavyalakshmi
}

\begin{abstract}
The purpose of this research paper is to design a drone which can move autonomously in a fixed predetermined route or by using radio waves through any environment. Various drones are available nowadays which differ in size, color and properties. Unmanned aerial vehicles have gained wide popularity over decades and are used extensively for several applications. The main feature of this drone is that it does not require any additional infrastructure to quickly register and monitor the object. The major motive is to get accuracy in rescue missions for accidents occurring at higher terrain as well as underwater. The main uniqueness is that it can move through air and water. An efficient algorithm is incorporated to reduce the complexity. The drone's database is developed using artificial intelligence which helps in faster recognition of the object.
\end{abstract}

Keywords: drone; environment; AI; algorithm

\section{INTRODUCTION}

Essentially, Drones are flying robots which are more formally known as Unmanned Aerial Vehicles (UAV's). They are usually very agile, fast and capable of exhibiting autonomous behavior. Drones are capable of performing operations which are hard to execute by human operators[2].They can either be controlled using a remote controller or can move autonomously with the help of software controlled flight plans working in conjunction with GPS. They are mostly used for military purposes and for various other commercial applications which include journalism, film making, scientific and agricultural research. Various drones are available now days with different features and abilities, but a drone which can move through air and water without any additional requirements has not yet been identified. A Multi Terrain Surveillance Drone has the ability to move through any environment independently. Its entire design and architectural arrangements are done in such a way that it is capable of carrying out a smooth motion in both the specified environments. It can be mainly used to rescue human lives at the time of accidents both at higher terrains as well as underwater and for other commercial purposes as well. A data base is created and loaded into the drone. This drone consists of a camera setup. So, the data being captured

Revised Manuscript Received on July 22, 2019.

Rohit N Nair, ECE Dept., ASIET, Matoor, Kalady, Ernakulam- 683574, rohitnirmalnair@gmail.com

Roy Baiju, ECE Dept., ASIET, Matoor, Kalady, Ernakulam683574,roychakiath 11

@gmail.com

Sreelakshmi L S., ECE Dept., ASIET, Matoor, Kalady, Ernakulam683574, sree24unnithan@gmail.com

V kavyalakshmi, ECE Dept., ASIET, Matoor, Kalady, Ernakulam683574, anandkavya269@gmail.com

Prasanth P Menon, Asst. Professor, ECE Dept., ASIET, Matoor, Kalady, Ernakulam- 683574, prasanth.ec@ adishankara.ac.in by the drone's camera is compared with this previously loaded database and the required action is carried out.

\section{PROBLEM STATEMEMT}

In the past few years, unmanned aerial vehicles or drones were commonly used for military purposes which were then expanded to higher levels of applications. Now days, due to a lot of accidents occurring mainly at the high terrain locations and underwater vessel accidents, it is necessary to develop a technology that can help in search and rescue missions quite efficiently. For this purpose, a drone can be used since it can fly in any direction in any extreme environments without any risk to the operator. Due to the current technology developments and the algorithms that are deployed in unmanned aerial vehicle, they perform autonomous operations and reduce the requirements of skilled operators to fly the drones, as well as cut cost. Therefore it is essential to develop a surveillance system especially in the field of disaster management scenarios. .

\section{EXISTING TECHNOLOGIES}

Drones are used in several fields but the main areas where the drone technology is currently employed are;

A. Defense: Drones are a part of the intelligent army that is responsible for the security and terrorism related challenges. They are used to enhance the capability to determine the threats to the country and destroy the same.

B Aerial photography: This application is mainly used for the purpose of media coverage which gives high clarity air footage. This is done with the help of advanced camera carrying drone units. Earlier some of the industries made use of helicopters to capture critical shots but after the development of these aerial vehicles, it became quite affordable and can move around easily and capture news clips.

C In the field of Agriculture: Drones helps to study the failing plants along with proper monitoring of irrigation systems. The large sized farms can be well monitored and all the important information regarding the spraying of fertilizers, pesticides for crops at right times are quickly updated with the help of the algorithm employed in the drone's database.

D Drones for Safety Surveillance: Drones can be used to report about the criminal activities in large gatherings and achieve public safety. With the help of crowd surveillance, they find applications in careful monitoring especially at the border areas so that that drugs and smugglers can be easily captured.

There are several drones designed with the motive of emergency response at the time of disaster and its aftermath.

1. A special operations vehicle was designed in 2017 popularly known

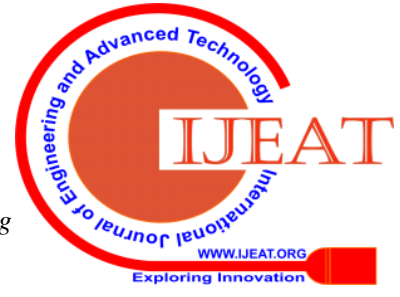


as "Project Hero" by Land Rover partnered with the Austrian Red Cross. It is basically a roof mounted, thermal imaging drone which is capable of identifying victims who are difficult to spot. This device has an integrated landing system which securely land atop the vehicle while in motion.

2. At the time of earthquake, specialized drones were designed to gather 3D images and the map of affected areas that can analyze the extent of damage caused and help in the rescue missions for the same [4].

\section{BENEFITS OF USING DRONE TECHNOLOGY IN DISASTER MANAGEMENT}

- Less exposure to workers and hence avoid unnecessary danger.

- Efficient means of data collection than ground based system.

- Unique viewing angles any fly in any direction

- Highly deployable

- Cost efficiency

- Relay on cellular phone service

- Wi-Fi and radio communications [2]

\section{PROPOSED DRONE}

There are a lot of situations where human beings cannot access specific locations like high terrains or under water. Search and recovery becomes highly difficult when such locations are prone to accidents. Nowadays various drones are seen to be available. But such a drone which can move through every environment is rare. Hence we have proposed the idea of a Multi Terrain Surveillance Drone. This drone, as the name suggest, is capable of moving through both air and water independently.

The ideology behind the multi-terrain surveillance drone is to use a dual camera setup as well as an algorithm using Artificial Intelligence for human detection and recognition system. It is further equipped with a light so as to provide better illumination to the field which helps in recognition. The drone can be controlled using a remote controller which consists of inbuilt RF transmitter and receiver. In underwater conditions, a cable is connected from the drone to a floating buoy so as to transmit data. The buoy then receives and transmits data using radio waves to the remote control.

The main motive is to get accuracy in rescue missions in the cases of accidents and make it easier than before. It is designed with an objective to search for missing humans in the aftermath of an accident occurring in any of the above mentioned terrains or locations.

\section{LAYOUT}

The layout of the Multi Terrain Surveillance Drone will be as follows:

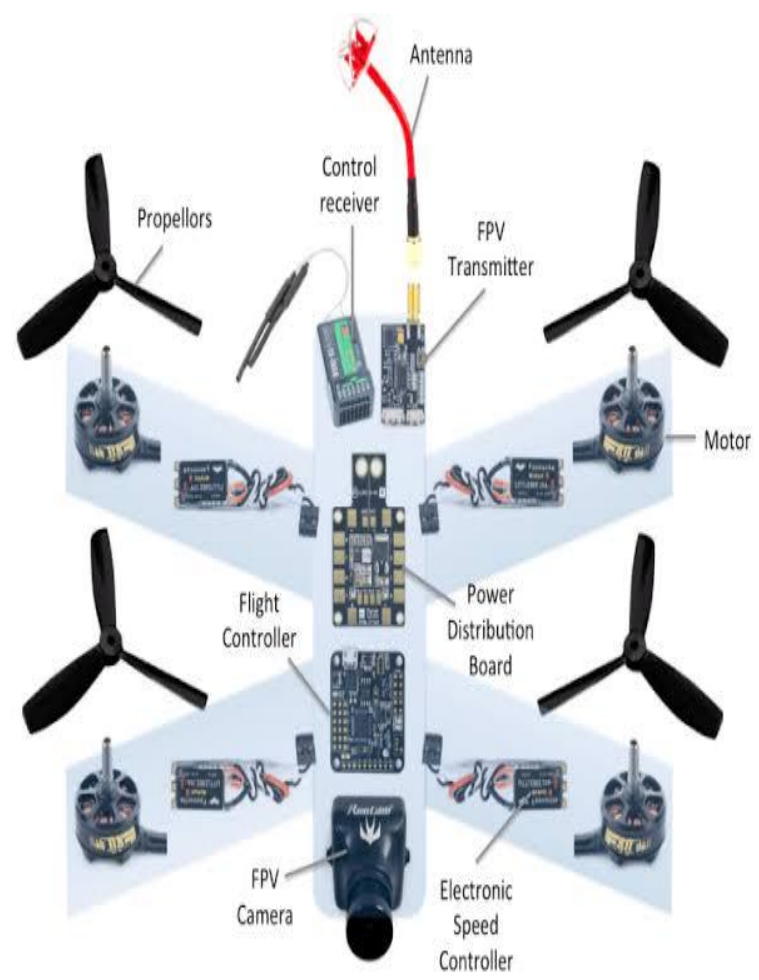

Fig 2: System Layout

\section{HARDWARE REQUIREMENTS}

The main components required for the construction of a Multi Terrain Surveillance Drone are [3]:

Motors (4 pcs): The attraction and repulsion of the magnets in a motor which occurs in a repetitive translates into a revolution of the shaft. So when a propeller is attached to the motor, it spins the propeller at a very high speed, thus producing a thrust.

Wireless transmitter receiver RF Module: Function is to transmit signals to the drone and receive signals from the drone.

GPS module: They use a constellation of satellites and ground stations to compute the required exact positions.

Flight control module: Basically a small circuit board. Its main function is to direct the RPM of each motor in response to the input.

Propellers: Functions include development of thrust and torque to keep the drone flying.

Camera: performing its normal function, capturing images.

Landing Gear: Basically represents the legs of the drone. They serve the purpose of aerial photography platforms.

Drone frame: It protects the delegate electrical components from harm and provides individualism and character to a build.

Electronic speed controller: Its function is to switch on power to motor coils at incredibly fast rates. 
Chargeable Battery: provides the necessary DC supply.

\section{CONCEPT DESIGN}

A questionnaire was prepared regarding the various design specifications that a customer would desire and the interpreted need is also highlighted in the table below:

\begin{tabular}{|c|c|c|}
\hline Questions & $\begin{array}{c}\text { Customer } \\
\text { Statement }\end{array}$ & $\begin{array}{c}\text { Interpreted } \\
\text { Need }\end{array}$ \\
\hline $\begin{array}{c}\text { How heavy or light } \\
\text { do you want the } \\
\text { device to be? }\end{array}$ & $\begin{array}{c}\text { The lighter, the } \\
\text { more better }\end{array}$ & Weight \\
\hline $\begin{array}{c}\text { How durable do you } \\
\text { want the device to } \\
\text { be? }\end{array}$ & $\begin{array}{c}\text { Durable enough to } \\
\text { sustain from } \\
\text { shock from } \\
\text { falling from a } \\
\text { small height }\end{array}$ & Durability \\
\hline $\begin{array}{c}\text { How would you like } \\
\text { to operate the } \\
\text { drone? }\end{array}$ & $\begin{array}{c}\text { Remote control } \\
\text { along with video } \\
\text { screen }\end{array}$ & Remote design \\
\hline $\begin{array}{c}\text { Any energy source } \\
\text { specifications? }\end{array}$ & $\begin{array}{c}\text { Battery, if } \\
\text { possible using } \\
\text { solar panels }\end{array}$ & Battery life \\
\hline $\begin{array}{c}\text { What other } \\
\text { capabilities would } \\
\text { you like? }\end{array}$ & $\begin{array}{c}\text { Camera, speaker, } \\
\text { carrier, dropper, } \\
\text { holder }\end{array}$ & Functionalities \\
\hline $\begin{array}{c}\text { How much cost do } \\
\text { you expect? }\end{array}$ & \$500 & Cost \\
\hline
\end{tabular}

Drone is designed in such a way that it meets almost all the desired specification given by the customer.

The design specifications include:

Drone is light enough to fulfill its functionality.

Drone is somewhat shock-resistant

Drone lasts more than 5 minutes

Drone has at least 3 functions

Drone has a long battery duration

Drone cost less than $\$ 500$

\section{SCIENTIFIC SCOPE}

Human life is one of the most valuable prospects. People die due to many unfortunate accidents occurring in remote places or difficult to reach areas. For example, in the aftermath of a water vessel accident, many people are drowned to death. These lives can be saved if we know the exact position of the person at that time, similarly in the occurrence of a flight crash in remote area where human access is difficult, Rescue operations can be made easier if the location of the people can be identified at the earliest. There are many existing drones, in which a few are used underwater and a few others are used for flight, but there are no existing drones which are capable of operating in all terrains [5].

Our idea is to develop a drone which can travel through any kind of terrain which is capable of detecting and identifying the presence of humans in the above mentioned situations. This drone is designed in such a way that it consists of an advanced dual camera setup with a flashlight of high intensity which is used to illuminate the surroundings that helps in better object detection and recognition. Artificial
Intelligence is implemented to improve object detection and autopilot functionality of the drone.

The drone will be capable of flying up to 5 kilometers without interference and up to $200 \mathrm{~m}$ underwater. While in flight mode, the drone uses the inbuilt RF transceiver to transmit data to a wireless remote controller. While in Dive mode, the drone is connected to a floating buoy via data link cable, which is retractable and housed in the buoy. Floating buoy houses a RF transceiver which can communicate with the remote controller.

\section{FUTURE DEVELOPMEMT}

One important upcoming technology that can be incorporated into the multi terrain surveillance drone is the wireless internet access. According to the recent study conducted, drones can be utilized to serve internet signal at remote locations. Since internet is one of the most useful technologies, such a development would be really useful in the rescue missions. The data can be sent online to any unnamed locations and the response can be delivered to the drone database in no time. The development can reach to a peak level that the mobile signal can be caught by a drone flying above in air.

\section{CONCLUSION}

In this paper, we have presented a drone which is capable of Multi Terrain Surveillance. The design and constructional aspects of the drone is in such a way that it is capable of smooth motion in both air and underwater up to the specified level. When compared to the existing technologies, this Multi Terrain Surveillance Drone is found to be more efficient and reliable. It is constructed considering the drawbacks of the existing technologies, so it is hereby capable of challenging the same and has the ability to take the technology to the next level. The system is expected to have a high scientific scope and can be modified with respect to the developing technologies in future [1].

\section{REFERENCES}

[1] Nahid Mahamud, Galib Muhammad Shahriar; "ALW drone: A new design and efficient approach", in [19th International Conference on Computer and Information Technology (ICCIT)], 2017 @ IEEE

[2] Chandykunju Alex, Aditya Vijaychandra; "Autonomous Cloud Based Drone System for disaster response and Mitigation", in [International Conference on Robotics and Automation for Humanitarian Applications (RAHA)], 2016 @ IEEE

[3] Juan A. Besada, Ana M. Bernardos; "Drones-as-a-service: A management architecture to provide mission planning, resource brokerage and operation support for fleets of drones",in [IEEE International Conference on Pervasive Computing and Communications Workshops (PerCom Workshops)] 2019 (C) IEEE

[4] Nguyen Dinh Dung, Jozsef Rohacs; "The drone-following models in smart cities", [ 59th International Scientific Conference on Power and Electrical Engineering of Riga Technical University (RTUCON)] 2019 (C) IEEE

[5] David Schneider; "Air traffic control for delivery drones", in[IEEE Spectrum(Volume: 54, Issue:1, January)] 2017 @ IEEE 


\section{AUTHORS PROFILE}

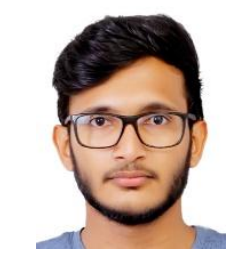

Rohit N Nair, Department of Electronics and Communication Engineering ,Adishankara Institute of Engineering and Technology, Matoor, Kalady, Ernakulam 683574.rohitnirmalnair@gmail.com

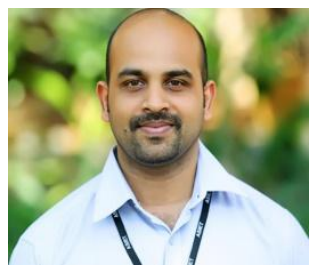

Prasanth P Menon, Asst Professor Department of Electronics and Communication Engineering ,Adishankara Institute of Engineering and Technology, Matoor, Kalady, Ernakulam - 683574.

Prasanth.ec@adishankara.ac.in

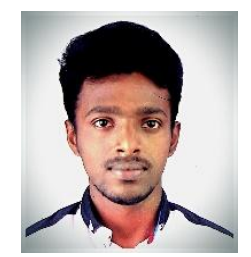

Roy Baiju, Department of Electronics and Communication Engineering, Adishankara Institute of Engineering and Technology, Matoor, Kalady, Ernakulam - 683574.

roychakiath11@gmail.com

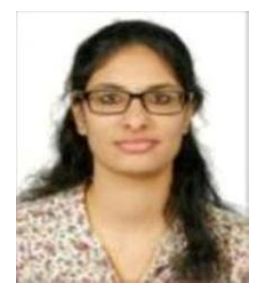

Sreelakshmi L S., Department of Electronics and Communication Engineering Adishankara Institute of Engineering and Technology, Matoor, Kalady, Ernakulam 683574.sree24unnithan@gmail.com

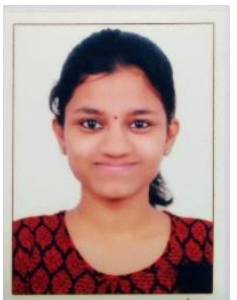

V Kavyalakshmi, Department of Electronics and Communication Engineering ,Adishankara Institute of Engineering and Technology, Matoor, Kalady, Ernakulam 683574.anandkavya269@gmail.com 